\title{
REFLEXÕES SOBRE SUSTENTABILIDADE: DUAS OBRAS ARQUITETÔNICAS SEPARADAS POR SETE DÉCADAS
}

\author{
ALBUQUERQUE, Rafael Tavares de \\ UFRJ, e-mail: raffa.tavares@yahoo.com.br \\ ANDRADE, Anick Martins de \\ UNIGRANRIO, e-mail: anickmartins@gmail.com \\ COUTO, Kurtiss \\ UNIGRANRIO, e-mail: kurtisscouto@gmail.com
}

\begin{abstract}
RESUMO
Com enfoque nos conceitos atuais de sustentabilidade e certificação ambiental, o estudo consiste na análise de duas edificações separadas no tempo por 70 anos desde suas construções originais, sendo uma pertencente ao movimento moderno (1941) e a outra uma edificação de arquitetura de mercado imobiliário de alto padrão da atualidade (2016). Este estudo apresenta uma análise de ambas as edificações através de um selo totalmente brasileiro, o SELO CASA AZUL (SCA) da Caixa Econômica Federal, voltado para edificações residenciais multifamiliares de interesse social. Apesar de atualmente, ambas não se enquadrarem na proposta social do selo, serão verificados os desempenhos de seus respectivos projetos frente a uma já consolidada e reconhecida certificação nacional. Com base nos resultados obtidos, pôde-se verificar como se comportou a edificação antiga, comparada a uma contemporânea, frente aos desafios impostos pelas extensas listas de quesitos e itens do selo SCA. Ambas edificações apresentam resultados, onde permitem reflexões sobre a pertinência do êxito sustentável diante de um selo ambiental.
\end{abstract}

Palavras-chave: Selo Casa Azul, Sustentabilidade, Movimento Moderno.

\begin{abstract}
With a focus on the current concepts of sustainability and environmental certification, the study consists of the analysis of two buildings separated in time by 70 years from their original constructions, one belonging to the modern movement (1941) and the other a building of real estate market architecture high standard (2016). This study presents an analysis of both buildings through a seal Brazilian, the SELO CASA AZUL (SCA) of Caixa Econômica Federal, focused on multifamily residential buildings of social interest. Although currently, both do not fit the social proposal of the seal, the performance of their respective projects will be checked against an already consolidated and recognized national certification. Based on the results obtained, it was possible to verify how the old building behaved, compared to a contemporary one, in front of the challenges imposed by the extensive lists of items and items of the seal SCA. Both buildings present results, where it allows reflections on the pertinence of sustainable success before an environmental seal.
\end{abstract}

Keywords: Casa Azul Seal, Sustainability, Modernism.

\section{INTRODUÇÃO}

Quando a arquitetura não acompanha a sociedade, esta corre um sério risco cometer falhas, se tornando obsoleta e encurtando seu tempo de ciclo de vida estimado. Projetar habitações destinadas a um modelo de família padrão, a um usuário médio que nunca vai existir, mostra uma despreocupação com o verdadeiro usuário final. (TRAMONTANO, 1993).

ALBUQUERQUE, R. T.; ANDRADE, A. M.; COUTO, K. Reflexões sobre Sustentabilidade: Duas Obras Arquitetônicas Separadas por Sete Décadas. In: SIMPÓSIO BRASILEIRO DE QUALIDADE DO PROJETO NO AMBIENTE CONSTRUÍDO, 6., 2019, Uberlândia. Anais... Uberlândia: PPGAU/FAUED/UFU, 2019. p. 520-531. DOI https://doi.org/10.14393/sbqp19049. 
O mercado imobiliário atualmente, concentra suas ações para rentabilizar seu capital de investimento, criando um círculo de produção imobiliária que define o tipo de projeto que deve ser realizado. A produção da habitação coletiva permanece materializada ainda por meio destes interesses de mercado que promovem a replicação de projetos já pré-concebidos, estes quase sempre, excluem o entendimento das necessidades reais do seu verdadeiro usuário.

Segundo Bacellar (2017), em um estudo onde é aplicado a edificações com mais de 50 anos, os critérios adotados pelo selo SCA, as construções possuem muitos desafios para atender aos critérios e requisitos da certificação. No entanto, a autora afirma que não é um cenário impossível, considerando as particularidades de cada edificação.

O processo SCA, em sua concepção, evidencia a necessidade de incorporar critérios relacionados ao conceito de flexibilidade de espaço para garantir o contínuo processo de qualificação ambiental do edifício (COSTA, 2014). O selo possui seis capítulos, divididos em 53 critérios que podem ser utilizados para a avaliação: Qualidade Urbana, Projeto e Conforto, Eficiência Energética, Conservação de Recursos Materiais, Gestão da Água e Práticas Sociais. A implementação da certificação busca o incentivo do uso racional de recursos ambientais na construção de empreendimentos habitacionais voltados ao setor social, a redução do custo de manutenção e das despesas mensais de operação de seus sistemas, bem como a promoção da conscientização de empreendedores e moradores sobre as vantagens das construções sustentáveis. $\bigcirc$ processo certificatório aplica-se a empreendimentos habitacionais financiados pela CEF, sendo a sua adesão voluntária (CAIXA ECONÔMICA FEDERAL, 2013).

No Brasil, desde 2007 alguns instrumentos de avaliação ambiental vêm sendo aplicados com o propósito de chancelar estes novos edifícios, dentre os selos, destacam-se: LEED, AQUA-HQE e Selo Casa Azul. Neste contexto, Figueiredo (2018), realizou estudos exploratórios sobre o uso dos instrumentos de certificação na produção habitacional do país, onde verificou que é possível certificar projetos de habitação social, embora seus resultados não garantam totalmente a melhoria da qualidade da arquitetura. Os selos ambientais, ainda que outorguem alguma melhoria ambiental, atuam como coadjuvantes e favorecem ao processo comercial contribuindo para o marketing da venda do empreendimento. (FIGUEIREDO, 2018)

Fastofski (2017) realizou uma pesquisa sobre o uso do SCA em empreendimentos habitacionais no Brasil, no quadro 1 a seguir estão relacionados pesquisas recentes e seus desdobramentos mais relevantes.

\section{Quadro 1 - Itens SCA - Qualidade Urbana}

\begin{tabular}{|c|c|c|}
\hline Autor & Ano & Assunto \\
\hline Magnani & 2011 & $\begin{array}{c}\text { Realizou uma comparação entre o Selo Casa Azul e o LEED for } \\
\text { Homes, apontando a importância da regionalização nos } \\
\text { critérios, mesmo que os dois sistemas incorporam aspectos } \\
\text { semelhantes. }\end{array}$ \\
\hline Figueira & 2012 & $\begin{array}{c}\text { Desenvolveu uma aplicação da metodologia SCA em um } \\
\text { projeto de padrão médio e concluiu que o Selo é uma } \\
\text { importante ferramenta para orientar a implementação de } \\
\text { construções mais sustentáveis. }\end{array}$ \\
\hline
\end{tabular}




\begin{tabular}{|c|c|c|}
\hline Vasconcelos & 2012 & $\begin{array}{c}\text { Analisou a possibilidade de aplicar os quesitos do SCA à } \\
\text { habitação social, verificando a possibilidade de promover um } \\
\text { ganho qualitativo no design do edifício. }\end{array}$ \\
\hline Silva & 2012 & $\begin{array}{c}\text { Aplicou o Selo em projetos de habitação para reassentamento. } \\
\text { Ele verificou a viabilidade social habitação e sugeriu a inclusão } \\
\text { de algumas novas condições para o êxito da sustentabilidade. }\end{array}$ \\
\hline Moreno & 2013 & $\begin{array}{c}\text { Analisou o desempenho térmico da Minha Casa Minha Vida } \\
\text { (MCMV), concluindo que um único projeto não pode atingir o } \\
\text { nível mínimo de desempenho dentro do país. }\end{array}$ \\
\hline $\begin{array}{c}\text { Bello, Sabacke } \\
\text { Costa }\end{array}$ & 2014 & $\begin{array}{c}\text { Verificou o SCA para dois projetos financiados pelo programa } \\
\text { MCMV, analisando os custos necessários para alcançar os } \\
\text { critérios obrigatórios. Os autores propuseram soluções para } \\
\text { melhorar projeto, a fim de atingir o nível de bronze. O mesmo } \\
\text { procedimento foi adotado para considerar soluções para } \\
\text { alcançar os critérios de livre escolha níveis de prata e ouro. }\end{array}$ \\
\hline
\end{tabular}

Fonte: Adaptado pelo autor (FASTOFSKI et al. 2017)

Discursos críticos sobre a pertinência das ações isoladas impostas pelos selos e o crescimento do marketing verde no mercado imobiliário atual, contribuem para um desgaste do termo "arquitetura sustentável". As edificações do parque Guinle são consideradas importantes referências da arquitetura praticada durante o movimento moderno no Rio de Janeiro. Se a ordem sustentável através de seus critérios pré-estabelecidos nos selos ambientais dita uma nova forma de se avaliar arquitetura, uma edificação construída a mais de 70 anos poderia estar em conformidade com as boas práticas atuais?

\section{OBJETIVO E METODOLOGIA}

Este recorte tem como objetivo principal evidenciar a importância da etapa de projeto de arquitetura no êxito da sustentabilidade final para o edifício. Apesar de ser apenas um estudo de caso de uma única edificação residencial multifamiliar do movimento moderno, as respostas desta pesquisa trazem uma importante reflexão sobre o papel do arquiteto diante dos desafios sustentáveis, muita das vezes, com escolhas limitadas pelos rigorosos checklists ambientais das certificações verdes.

Nesta simulação de certificação, foi realizado um estudo de caso comparativo, analisando duas habitações contemporâneas multifamiliares, a primeira da década de 50, expressiva pelo seu histórico valor arquitetônico pertencente ao movimento da arquitetura moderna e a segunda contemporânea aos nossos dias atuais, seguindo os padrões característicos da arquitetura de mercado imobiliário de alto padrão (2016).

A primeira edificação escolhida foi o edifício Nova Cintra (figura 1), um dos blocos residenciais projetados por Lúcio Costa, na década de 40 no Parque Guinle da cidade do Rio de Janeiro. O local foi concebido pelos arquitetos Armando Telles, Gire e Bovet e o projeto realizado em 1916. Como elemento central, o parque original possui uma mansão residencial, hoje, conhecida como o Palácio das Laranjeiras, sede do Governo do Estado do Rio de Janeiro. Depois do falecimento de Eduardo Guinle, em 1941, seus herdeiros resolveram construir em anexo, um conjunto habitacional seguindo os princípios da arquitetura moderna. 


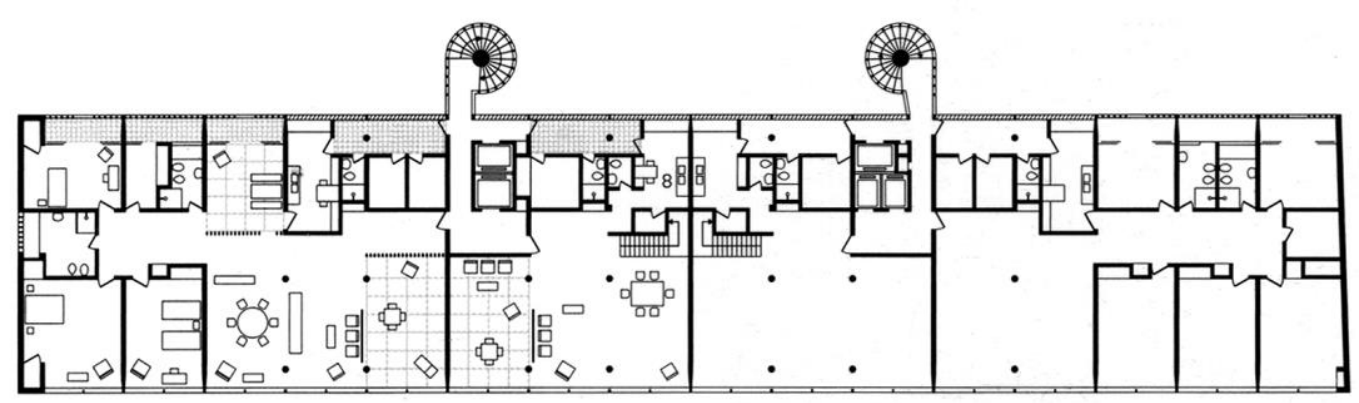

$\lambda \mathrm{N} O \longrightarrow 10 \mathrm{~m}$

Figura 1 - Planta do $2^{\circ}, 4^{\circ}$ e $6^{\circ}$ pavimentos do Edifício Nova Cintra

Fonte: https://www.archdaily.com.br/br/01-14549/classicos-da-arquitetura-parque-guinle-luciocosta/planta-2-4-6/ (consultado em 2019)

A segunda edificação para este estudo de caso foi um edifício contemporâneo do Condomínio Saint Michel (figura 2) no bairro planejado de Ilha Pura, na Barra da Tijuca. Está localizado na região de Jacarepaguá e foi construído pelas incorporadoras Carvalho Hosken e Odebrecht Realizações Imobiliárias. A edificação da Barra da Tijuca obteve êxito na certificação LEED, sendo classificada como PLATINA. Em 2016, o bairro abrigou os atletas olímpicos e paraolímpicos, atendendo aos mais altos padrões de sustentabilidade e gestão de recursos, segundo os conceitos contemporâneos. O bairro tem mais de $800.000 \mathrm{~m}^{2}$ norteados pelo conceito da sustentabilidade.

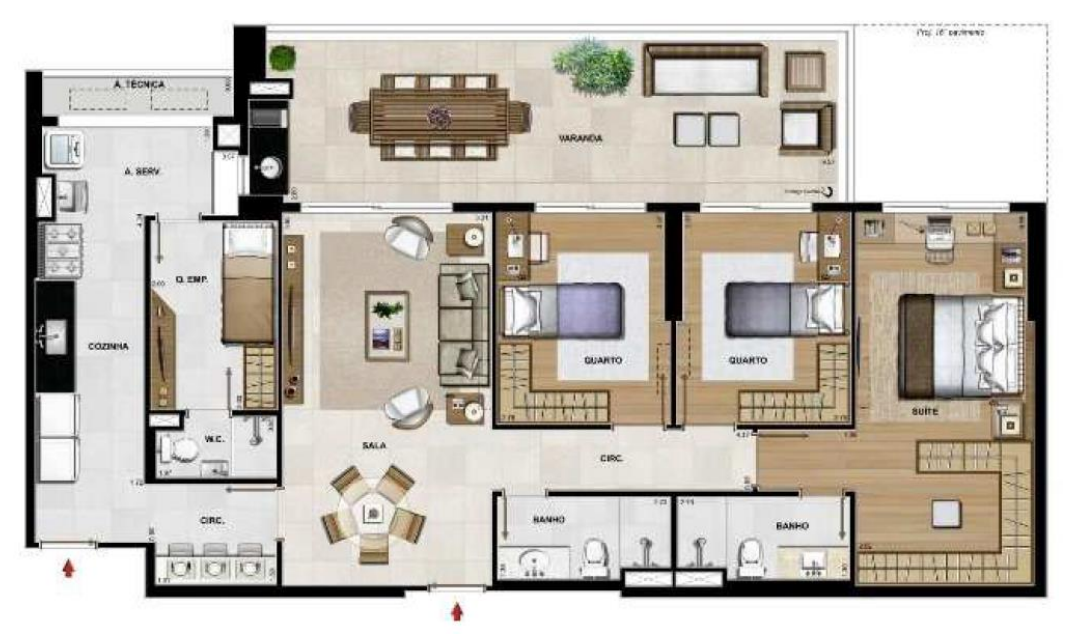

Figura 2 - Planta Edifício Alsace - Saint Michel

Fonte: http://egcorretora.com/saint-michel-barra-da-tijuca-ilha-pura-apartamento.html (consultado em 2019)

A pesquisa confrontou de forma comparativa ambas as edificações sob seus aspectos gerais projetuais sob os quesitos de exigência da Certificação Ambiental Nacional SELO CASA AZUL (SCA), aplicando aos projetos em questão todos os seus critérios, verificado a viabilidade em atender, possivelmente atender ou não atender cada um dos requisitos do selo. Através de análise das plantas arquitetônicas (figura 1 e 2) de ambos os projetos, foi utilizado como roteiro o manual oferecido gratuitamente pelo site da Caixa Econômica Federal e através de uma leitura criteriosa, aplicado item a item analisando ambas as edificações. Ao logo do artigo, será apresentado em 
tabelas, todos os quesitos com cada um dos itens, verificado o êxito de cada um deles no processo de análise de ambos os projetos.

O SCA (figura 3) foi desenvolvido pelo Banco Caixa Econômica Federal (CEF) em 2010 e é o primeiro reconhecido instrumento de classificação socioambiental de projetos habitacionais nacionais, direcionado para 0 contexto habitacional no Brasil. O objetivo da certificação é reconhecer nos projetos habitacionais, as contribuições para a redução dos impactos ambientais.

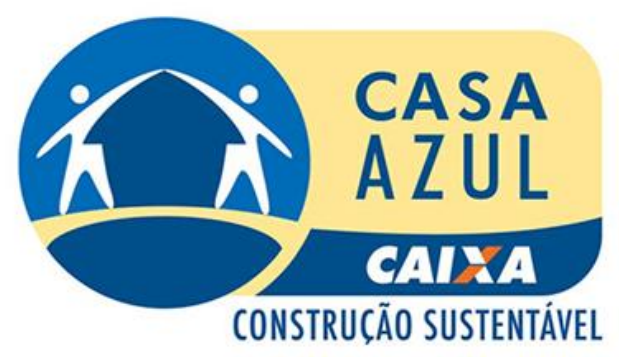

Figura 3 - Logomarca do SELO AZUL da CAIXA retirado do seu site oficial

Fonte: http://www.labeee.ufsc.br/projetos/manual-selo-casa-azul-caixa (consultado em 2019)

O processo de certificação possui três níveis de êxito, sendo eles: ouro, prata e bronze. A obtenção da certificação depende da quantidade de critérios atendidos pelo empreendimento solicitante, que pode obter auxílios através de um manual fornecido pela própria entidade chamado de: "Guia CAIXA de Sustentabilidade Ambiental - Selo Casa Azul".

A certificação possui seis capítulos, divididos em 53 critérios que podem ser utilizados para a avaliação: Qualidade Urbana, Projeto e Conforto, Eficiência Energética, Conservação de Recursos Materiais, Gestão da Água e Práticas Sociais. A implementação do selo busca o incentivo do uso racional de recursos ambientais na construção de empreendimentos habitacionais, a redução do custo de manutenção e das despesas mensais de operação de seus sistemas, bem como a promoção da conscientização de empreendedores e moradores sobre as vantagens das construções sustentáveis. O processo certificatório aplica-se a empreendimentos habitacionais financiados pela CEF, sendo a sua adesão voluntária (CAIXA ECONÔMICA FEDERAL, 2018)

Os resultados oferecem reflexões importantes sobre a capacidade de um projeto da década de $50 \mathrm{em}$ atender aos rigorosos e pragmáticos padrões exigidos pelo selo e apresenta uma reflexão sobre o desempenho comparativo às duas edificações extemporâneas, além da postura do arquiteto diante dos desafios sustentáveis de nossos dias atuais.

\section{ANÁLISE DE RESULTADOS}

A partir da análise e aplicação do manual do SCA em ambas as edificações foi elaborada uma tabela para cada uma das edificações onde apresentam as respostas em "atende", "parcialmente" ou "não atende".

Para a categoria "atende", foram classificados os quesitos que possuem plenamente a capacidade de atender ao quesito sem modificações em 
projeto ou reforma da edificação original de cada um dos exemplares. Para a categoria "possivelmente atende" foram aplicados aos quesitos que poderiam atender à exigência do selo ambiental através de ações factíveis e viáveis, ou através de intervenções diretas nas edificações existentes. Para a última categoria "não atende", foram atribuídos aos quesitos nos quais eram impossibilitados de se cumprir, diante da condição já edificada de cada um dos exemplares. Abaixo nas tabelas pode-se observar os resultados de cada um dos quesitos do SCA para cada uma das edificações: Nova Cintra e Saint Michel.

\subsection{Quesito 1 - Nível 1: Qualidade Urbana}

A proposta deste quesito consiste em verificar a inserção do empreendimento na malha urbana existente, contribuindo para que os recursos públicos e privados possam ser mais bem direcionados para a melhoria dos serviços já existente no bairro. O item 1.1 e 1.2 são obrigatórios para a certificação.

Tabela 1 - Qualidade Urbana

\begin{tabular}{|c|c|c|c|c|}
\hline \multirow{2}{*}{ Item } & \multirow{2}{*}{ Nível 2} & \multirow{2}{*}{ Nível 3} & \multicolumn{2}{|c|}{ Classificação } \\
\hline & & & NOVA CINTRA & SAINT MICHEL \\
\hline \multirow{9}{*}{1.1} & Entorno/Infraestr. & Pavimentação & Atende & Atende \\
\hline & Entorno/Infraestr. & Energia Elétrica & Atende & Atende \\
\hline & Entorno/Infraestr. & Iluminação Pública & Atende & Atende \\
\hline & Entorno/Infraestr. & Tratamento Esgoto & Atende & Atende \\
\hline & Entorno/Infraestr. & Transporte Público & Atende & Atende \\
\hline & Entorno/Infraestr. & Ponto de Comércio & Atende & Atende \\
\hline & Entorno/Infraestr. & Escola Pública & Atende & Atende \\
\hline & Entorno/Infraestr. & Equip. de Saúde & Atende & Atende \\
\hline & Entorno/Infraestr. & Equip. de Lazer & Atende & Atende \\
\hline \multirow{2}{*}{1.2} & Impactos & Ruídos Excessivos & Atende & Atende \\
\hline & Impactos & Odores Excessivos & Atende & Atende \\
\hline 1.3 & Melhoria Entorno & Previsão Projetos & Parcialmente & Atende \\
\hline 1.4 & Áreas Degradadas & Recuperação & Não Atende & Não Atende \\
\hline 1.5 & Reabilitação & Reabilitação & Atende & Não Atende \\
\hline
\end{tabular}

Fonte: http://www.labeee.ufsc.br/projetos/manual-selo-casa-azul-caixa, consultado em abril de 2018

Observando a tabela 2, verifica-se que ambas as edificações atendem aos quesitos obrigatórios do selo e apresentam desempenhos similares, deixando de atender a apenas dois itens em cada edificação.

\subsection{Quesito 2 - Nível 1: Projeto e Conforto}

A proposta deste quesito consiste em adequar as edificações as condições favoráveis de acordo com os preceitos característicos da arquitetura bioclimática, propondo estratégias climáticas, flexibilidade em projeto, iluminação e ventilação naturais, relação com o entorno, paisagismo e transporte eficientes. O item 2.1, 2.5, 2.6. 2.7, 2.8 são obrigatórios para a certificação. 
Tabela 2 - Projeto e Conforto

\begin{tabular}{|c|c|c|c|c|}
\hline \multirow{2}{*}{ Item } & \multirow{2}{*}{ Nível 2} & \multirow{2}{*}{ Nível 3} & \multicolumn{2}{|c|}{ Classificação } \\
\hline & & & NOVA CINTRA & SAINT MICHEL \\
\hline \multirow{2}{*}{2.1} & \multirow{2}{*}{ Paisagismo } & Arborização & Parcialmente & Atende \\
\hline & & Cobertura Verde & Parcialmente & Atende \\
\hline \multirow{2}{*}{2.2} & \multirow{2}{*}{ Flexibilidade } & Ampliações & Atende & Parcialmente \\
\hline & & Adaptações & Atende & Parcialmente \\
\hline \multirow{4}{*}{2.3} & \multirow{4}{*}{ Vizinhança } & Insolação & Atende & Atende \\
\hline & & Luminosidade & Atende & Atende \\
\hline & & Ventilação & Atende & Atende \\
\hline & & Vistas Panorâmicas & Atende & Atende \\
\hline \multirow{3}{*}{2.4} & \multirow{3}{*}{ Transporte } & \multirow{3}{*}{ Bicicletários } & Atende & Atende \\
\hline & & & Atende & Atende \\
\hline & & & Atende & Atende \\
\hline \multirow{3}{*}{2.5} & \multirow{3}{*}{ Coleta Seletiva } & Coleta & Não Atende & Atende \\
\hline & & Seleção & Não Atende & Atende \\
\hline & & Armazenagem & Não Atende & Atende \\
\hline \multirow{7}{*}{2.6} & \multirow{7}{*}{ Equipos de Lazer } & Bosques & Atende & Atende \\
\hline & & Ciclovias & Atende & Atende \\
\hline & & Quadra Poliesport. & Atende & Atende \\
\hline & & Sala de Ginástica & Atende & Atende \\
\hline & & Salão de Jogos & Atende & Atende \\
\hline & & Sala de Festas & Atende & Atende \\
\hline & & Recreação Infantil & Atende & Atende \\
\hline 2.7 & \multirow{2}{*}{$\begin{array}{l}\text { Desempenho } \\
\text { Térmico }\end{array}$} & Vedações & Sem Análise & Sem Análise \\
\hline 2.8 & & Orientação Solar & Atende & Atende \\
\hline \multirow{2}{*}{2.9} & \multirow{2}{*}{$\begin{array}{l}\text { lluminação Áreas } \\
\text { Comuns }\end{array}$} & Luz Natural & Atende & Parcialmente \\
\hline & & Vãos Mínimos 12,5\% & Atende & Parcialmente \\
\hline 2.10 & Banheiros & Vent. E llum. natural & Atende & Parcialmente \\
\hline 2.11 & Condições Terreno & Benefícios Sociais & Atende & Não Atende \\
\hline
\end{tabular}

Fonte: http://www.labeee.ufsc.br/projetos/manual-selo-casa-azul-caixa, consultado em abril de 2018

Com relação ao quesito 2 , ambas as edificações atenderam a maioria dos itens, sendo que o Nova Cintra não atendeu a um quesito obrigatório referente a implementação de um espaço para reciclagem de lixo na concepção original de projeto. Com relação ao item 2.7, não foi possível acesso a especificações precisas do projeto original que possibilitassem a avaliação em equivalência de ambas as edificações, por consequência, o item não foi avaliado nesta comparação direta.

\subsection{Quesito 3 - Nível 1: Eficiência Energética}

A proposta deste quesito consiste em avaliar as edificações quanto aos equipamentos utilizados, fontes de energia, iluminação e dispositivos de acionamento e controle. Os itens 3.1 (obrigatório apenas para habitação de interesse social, até 3 salários mínimos), 3.2, 3.5 são obrigatórios para a certificação. Foram avaliados todos os níveis de ambas as edificações. 
Tabela 3 - Eficiência Energética

\begin{tabular}{|c|c|c|c|}
\hline \multirow{2}{*}{ Item } & \multirow{2}{*}{ Nível 2} & \multicolumn{2}{|c|}{ Classificação } \\
\hline & & NOVA CINTRA & SAINT MICHEL \\
\hline 3.1 & Lâmpadas & Parcialmente & Parcialmente \\
\hline 3.2 & Dispositivos & Parcialmente & Atende \\
\hline 3.3 & Aquecimento Solar & Parcialmente & Atende \\
\hline 3.4 & Aquecimento a Gás & Atende & Atende \\
\hline 3.5 & Medição Individualizada Gás & Atende & Atende \\
\hline 3.6 & Elevadores Eficientes & Não Atende & Atende \\
\hline 3.7 & Eletrodomésticos Eficientes & Parcialmente & Parcialmente \\
\hline 3.8 & Fontes de Energia Alternativa & Não Atende & Parcialmente \\
\hline
\end{tabular}

Fonte: http://www.labeee.ufsc.br/projetos/manual-selo-casa-azul-caixa, , consultado em abril de 2018

O edifício Nova Cintra enfrentou dificuldades em atender os itens deste quesito, a demanda tecnológica da exigência do selo foi além das limitações do projeto da década de 50. Apesar disso, os quesitos obrigatórios poderiam ser atendidos sem dificuldades em adaptações locais.

\subsection{Quesito 4 - Nível 1: Conservação e Recursos Materiais}

Quesito referente ao uso de materiais com certificações ambientais em suas composições e classificações e adoção de medidas tecnológicas de controle e análise de composição de fábrica dos insumos da construção. Os itens 4.2, 4.4 e 4.5 são obrigatórios neste quesito para a certificação.

Tabela 4 - Conservação e Recursos Materiais

\begin{tabular}{|c|c|c|c|}
\hline \multirow{2}{*}{ Item } & \multirow{2}{*}{ Nível 2 } & \multicolumn{2}{c|}{ Classificação } \\
\cline { 3 - 4 } & Coordenação Modular & NOVA CINTRA & SAINT MICHEL \\
\hline 4.1 & Não Atende & Não Atende \\
\hline 4.2 & Qualidade de Materiais e Componentes & Atende & Atende \\
\hline 4.3 & Componentes Industrializados ou Préfab. & Não Atende & Não Atende \\
\hline 4.4 & Fôrmas e Escoras Reutilizáveis & Não Atende & Atende \\
\hline 4.5 & Gestão de Resíduos & Não Atende & Atende \\
\hline 4.6 & Concreto com dosagem otimizada & Não Atende & Atende \\
\hline 4.7 & Cimentos CP-III e CP-IV & Não Atende & Atende \\
\hline 4.8 & Pavimentação com RCD & Não Atende & Não Atende \\
\hline 4.9 & Madeira Certificada ou Plástica & Não Atende & Atende \\
\hline 4.10 & Medição de Água Individualizada & Atende & Atende \\
\hline
\end{tabular}

Fonte: http://www.labeee.ufsc.br/projetos/manual-selo-casa-azul-caixa, consultado em abril de 2018

Conforme verificado na tabela 4, o edifício Nova Cintra não atendeu a dois dos três quesitos obrigatórios e seu desempenho foi muito fraco devido à falta de controle tecnológico dos materiais utilizados no projeto de arquitetura original.

\subsection{Quesito 5 - Nível 1: Gestão de Água}

A proposta deste quesito consiste em adequar as edificações as condições utilização e aplicação dos recursos hídricos do projeto. Os itens 5.1, 5.2 e 5.8 são obrigatórios para a certificação. 
Tabela 5 - Gestão de Água

\begin{tabular}{|c|c|c|c|}
\hline \multirow{2}{*}{ Item } & \multirow{2}{*}{ Nível 2 } & \multicolumn{2}{c|}{ Classificação } \\
\cline { 3 - 4 } & Medição Individualizada & NOVA CINTRA & SAINT MICHEL \\
\hline 5.1 & Sistemas de Economia: Descarga & Parcialmente & Atende \\
\hline 5.2 & Sistemas de Economia: Arejadores & Parcialmente & Não Atende \\
\hline 5.3 & Registros Reguladores de Vazão & Parcialmente & Não Atende \\
\hline 5.4 & Reuso de Águas Pluviais & Não Atende & Parcialmente \\
\hline 5.5 & Retenção de Águas Pluviais & Não Atende & Parcialmente \\
\hline 5.6 & Infiltração de Águas Pluviais & Atende & Parcialmente \\
\hline 5.7 & Áreas Permeáveis & Atende & Atende \\
\hline 5.8 & & &
\end{tabular}

Fonte: http://www.labeee.ufsc.br/projetos/manual-selo-casa-azul-caixa, consultado em abril de 2018

Conforme verificado na tabela 5, o Nova Cintra atendeu a maioria dos quesitos obrigatórios. As bonificações referentes às práticas sustentáveis em ações tecnológicas recentes como as medições individualizadas e retenção e reuso de águas pluviais foram decisivas para o atendimento mínimo do quesito.

\subsection{Quesito 6 - Nível 1: Práticas Sociais}

A proposta deste quesito consiste em proporcionar melhoria de condições para os trabalhadores da obra e para os moradores do empreendimento adotando práticas que valorizem o viés social do projeto. Os itens 6.1, 6.2 e 6.7 são obrigatórios para a certificação.

Tabela 5 - Práticas Sociais

\begin{tabular}{|c|c|c|c|}
\hline \multirow{2}{*}{ Item } & \multirow{2}{*}{ Nível 2} & \multicolumn{2}{|c|}{ Classificação } \\
\hline & & NOVA CINTRA & SAINT MICHEL \\
\hline 6.1 & Educação para Gestão de RCD & Não Atende & Atende \\
\hline 6.2 & Educação Ambiental dos Empregados & Não Atende & Atende \\
\hline 6.3 & Desenvolvimento dos Empregados & Não Atende & Atende \\
\hline 6.4 & Capacitação dos Empregados & Não Atende & Atende \\
\hline 6.5 & Inclusão de Trabalhadores Locais & Não Atende & Parcialmente \\
\hline 6.6 & Participação da Comunidade & Não Atende & Não Atende \\
\hline 6.7 & Orientação aos Moradores & Não Atende & Atende \\
\hline 6.8 & Educação Ambiental aos Moradores & Não Atende & Não Atende \\
\hline 6.9 & Capacitação na Gestão & Não Atende & Não Atende \\
\hline 6.10 & Mitigação de Riscos Sociais & Não Atende & Atende \\
\hline 6.11 & Geração de Emprego e Renda & Não Atende & Não Atende \\
\hline
\end{tabular}

Fonte: http://www.labeee.ufsc.br/projetos/manual-selo-casa-azul-caixa, consultado em abril de 2018

Como evidente na tabela 6, o edifício Nova Cintra não atendeu a nenhum item deste quesito, evidenciando a valorização das propostas sociais intrínsecas nos checklists ambientais dos selos sustentáveis. Projetos com recorrência em práticas sustentáveis, como a Edificação do Saint Michel, já 
avaliada sob a ótica do LEED, obtive êxito em grande parte dos itens deste quesito.

\section{CONSIDERAÇÕES FINAIS}

Conforme verificou-se nos gráficos 01, 02 e 03, o edifício do Saint Michel atendeu a maior parte dos requisitos do selo, isto se deve, certamente, devido ao seu êxito já consumado na certificação LEED-PLATINA do Condomínio da Ilha Pura. Já o edifício do Parque Guinle, o seu desempenho apesar de menos expressivo que a edificação da Barra da Tijuca, obteve êxito na certificação brasileira na maioria dos requisitos oferecidos pelo selo. Por se tratar de uma edificação com mais de 70 anos, o desempenho sustentável através do elo SCA, apesar de se caracterizar como "não certificado", o resultado foi bastante favorável, indicando a boa capacidade da proposta apresentada pela arquitetura moderna em atender as atuais demandas ambientais.

\section{Gráfico 01- SCA no Saint Michel}

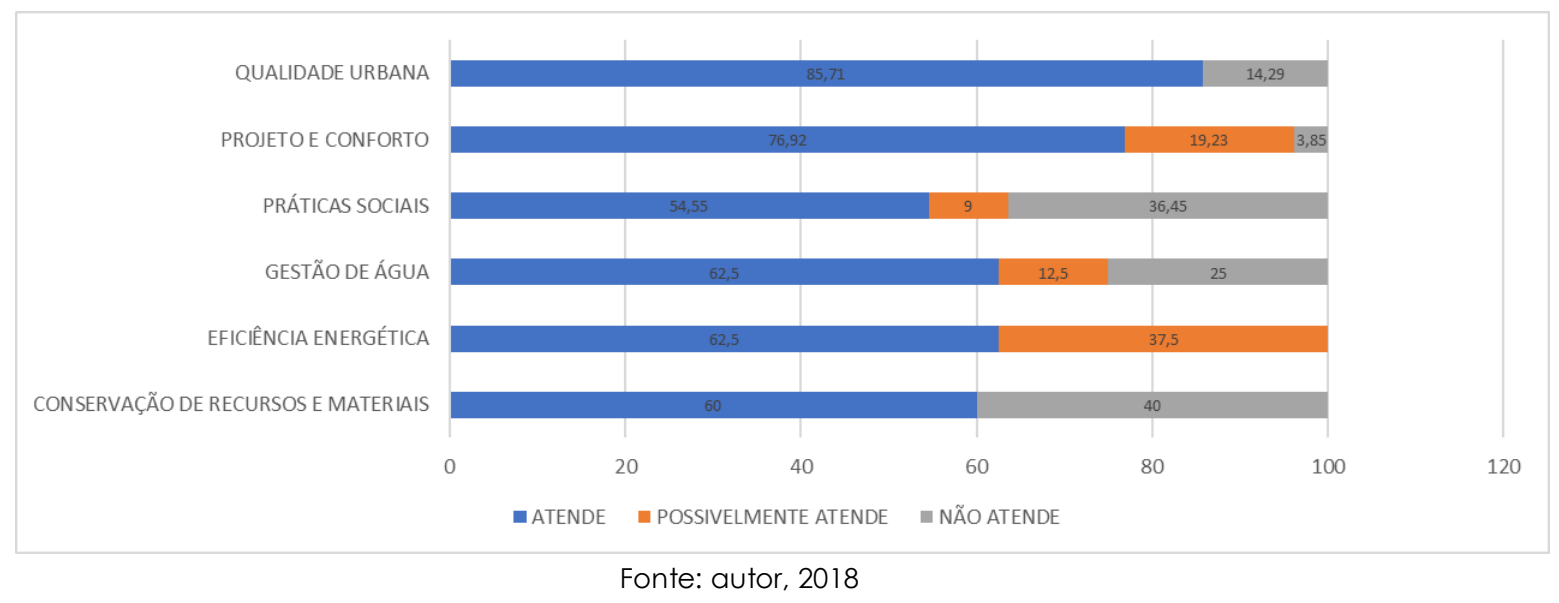

\section{Gráfico 02 - SCA no Nova Cintra}

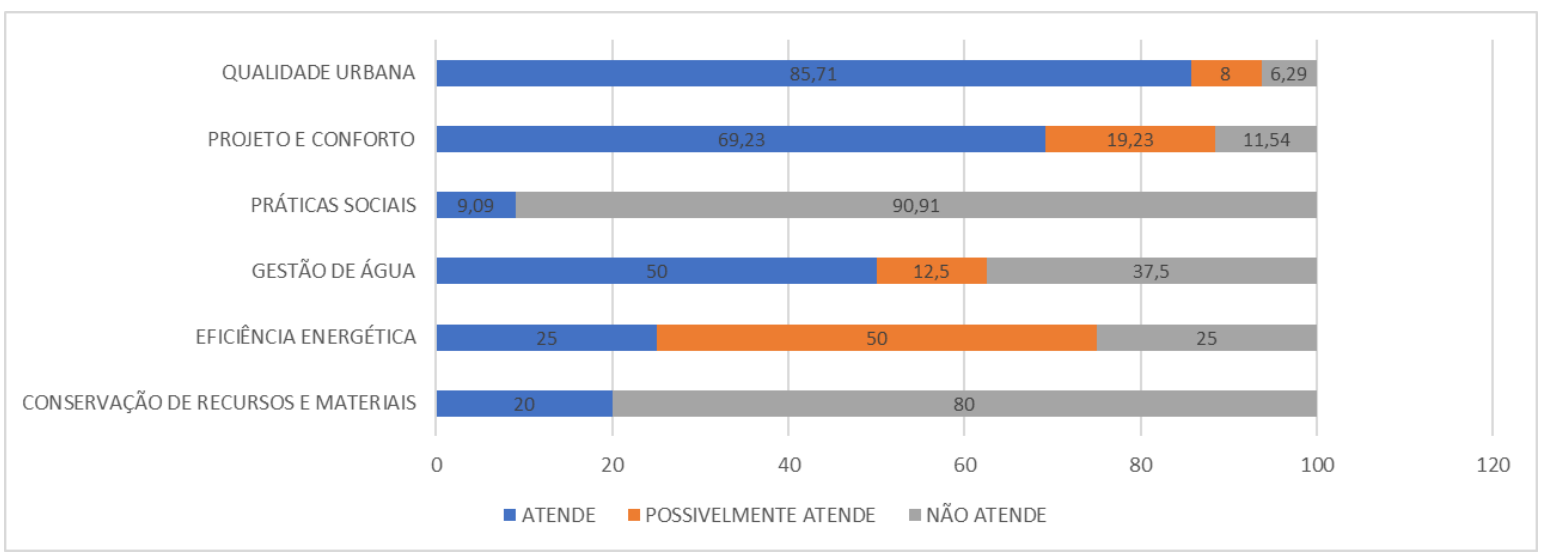

Fonte: autor, 2018 
Gráfico 03: Comparação do desempenho SCA das edificações.

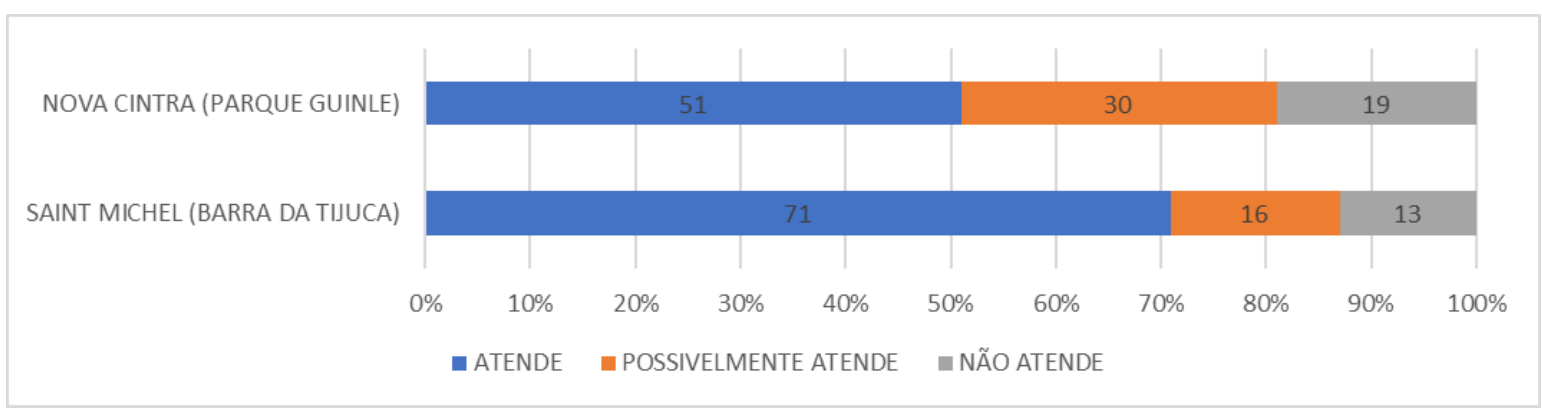

Fonte: autor, 2018

Conforme analisado no quesito 2, o Nova Cintra é de fato mais flexível do que o projeto do Saint Michel. Isto ocorre por conta da sua qualidade projetual, intrínseca nas questões evidentes do movimento moderno, adotadas na ocasião por Lúcio Costa. O Saint Michel em sua concepção de planta e distribuição de ambientes, segue ao um padrão básico do mercado imobiliário atual. Seu ponto focal tende a ser uma edificação tecnológica e eco eficiente e por esta razão foi exclusivamente projetado para cumprir esta função. Na Aplicação do SCA, o Nova Cintra foi avaliado sem nenhum tipo de reforma, mesmo assim, seu desempenho atendeu a maioria dos quesitos sustentáveis do selo.

Fica evidente que a proposta dos selos ambientais traz reflexões interessantes e pertinentes aos problemas enfrentados atualmente pela sociedade, questões de recursos naturais, gestão de resíduos e participação da sociedade são fatores imprescindíveis aos projetos de hoje. Mas fica também demonstrado que os itens tecnológicos são fortes alicerces do mérito certificatório oferecidos pelos selos. A boa prática de projeto pode também contribuir para uma classificação mais sustentável de uma edificação, mesmo sem as tecnologias e as mercadorias pontuadas pelos selos.

Esta pesquisa abre precedente para novos estudos exploratórios de outros projetos do passado sob o olhar dos selos ambientais da atualidade verificando assim suas pertinências ao êxito do mérito sustentável desejado.

\section{AGRADECIMENTOS}

À UNIGRANRIO, à UFRJ- PROARQ-FAU, aO CNPq e à CAPES, pelo apoio recebido; etc.

\section{REFERÊNCIAS}

BACELLAR, Marina R.M.F. Análise de Edifícios de Apartamentos Existentes no Rio de Janeiro com Aplicação de Certificação para Sustentabilidade. 2017. Dissertação de Mestrado. Programa de Pós-Graduação em Engenharia Urbana e Ambiental da PUC-Rio.

BELLO, A. A. C., SABACK, V. F., \& COSTA, D. B. Análise da viabilidade econômica de certificação ambiental de empreendimentos habitacionais de interesse social na região metropolitana de Salvador e BA. 2014. Coleção

Prêmio Odebrecht para Desenvolvimento Sustentável. (pp. 70e95). São Paulo. 
CAIXA ECONÔMICA FEDERAL. SELO CASA AZUL: Manual do Selo Casa Azul, 2013. Disponível em:

<https://www.caixa.gov.br/Downloads/selo_casa_azul/Beneficios_selo-casaazul.pdf>. Acesso em: janeiro 2019.

FASTOFSKI, D. C., GONZÁLEZ, M. A. S., \& KERN, A. P. Sustainability analysis of housing developments through the Brazilian environmental rating system Selo Casa Azul. 2017. Habitat International, 67, 44-53.

FIGUEIRA, A. C. Aplicação do Selo Casa Azul Caixa na construção civil: Estudo de caso de uma educação residencial. 2012. São Leopoldo, Brasil: Curso de Engenharia Civil, Universidade do Vale do Rio dos Sinos.

FIGUEIREDO, A. C. C. Certificação ambiental e habitação no Brasil: agentes e requisitos urbanísticos e arquitetônicos. 2018. 189f. Dissertação de Mestrado Pós-Graduação em Arquitetura e Urbanismo da USP, São Paulo.

FOLZ, Rosana Rita. Projeto tecnológico de habitação mínima e seu mobiliário. 2008. 671f. Tese de Doutorado - Pós-Graduação em Arquitetura e Urbanismo, Universidade de São Carlos, São Paulo.

MAGNANI, J. M. Análise comparativa do Selo Casa Azul com o sistema de certificação LEED for Homes. 2011 . Dissertação de MBA. Belo Horizonte: UFMG.

MORENO, A. C. R. Minha Casa Minha Vida: análise de desempenho térmico pela NBR 15.220-3, NBR 15.575, Selo Casa Azul e RTQ-R. 2013. Dissertação de Mestrado em Arquitetura. Belo Horizonte, Brasil: UFMG

SILVA, M. R. S. da. Análise das práticas de sustentabilidade do assentamento margem esquerda em Gaspar/SC: Utilizando os critérios do Selo Casa Azul. 2012. Dissertação de Mestrado em Arquitetura. UFSC, Florianópolis.

TRAMONTANO, Marcelo. Espaços domésticos flexíveis: notas sobre a produção da primeira geração de modernistas brasileiros. 1993a, 15p. Texto técnico - São Paulo: FAU/USP.

USGBC. LEED V4 for Building Design and Construction, 2019. Disponível em: $<$ https://www.usgbc.org/resources/leed-v4-building-design-and-constructioncurrent-version>. Acesso em: janeiro 2019.

VASCONCELOS, L. B. de. Análise da aplicação do Selo Casa Azul da Caixa Econômica Federal em empreendimentos de habitação de interesse social. 2012. II Congresso Internacional Sustentabilidade e Habitação de Interesse Social. Porto Alegre, Brasil: EdiPUCRS. 